\title{
Differential expression of c-Ret in motor neurons versus non-neuronal cells is linked to the pathogenesis of ALS
}

Hoon Ryu ${ }^{1,2,3, *}$, Gye Sun Jeon ${ }^{2 \star}$, Neil R Cashman ${ }^{4}$, Neil W Kowall ${ }^{1,3}$ and Junghee Lee ${ }^{1,3}$

Amyotrophic lateral sclerosis (ALS) is a fatal neurological disorder characterized by selective degeneration of motor neurons throughout the central nervous systems. Non-cell autonomous damage induced by glial cells is linked to the selective susceptibility of motor neurons in ALS, but the mechanisms underlying this phenomenon are not known. We found that the expression of non-phosphorylated and phosphorylated forms (tyrosine (Tyr) residue 905, 1016, and 1062) of c-Ret, a member of the glial cell line-derived neurotrophic factor (GDNF) receptor, are altered in motor neurons of the lumbar spinal cord in ALS transgenic (G93A) mice and ALS (G93A) cell line models. Phosphorylated forms of c-Ret were colocalized with neurofilament aggregates in motor neurons of ALS mice. Consistent with the in vivo data, levels of non-phosphorylated and phosphorylated c-Ret (Tyr 905, 1016, and 1062) were decreased by oxidative stress in motor neuronal cells (NSC-34). Non-phosphorylated and phosphorylated forms of c-Ret immunoreactivity were markedly elevated in active microglia of ALS mice. Our findings suggest that constitutive oxidative stress modulates c-Ret function, thereby reducing GDNF signaling in motor neurons. Furthermore, the induction of c-Ret expression in microglia may contribute to non-cell autonomous cell death of motor neurons by available GDNF in ALS.

Laboratory Investigation (2011) 91, 342-352; doi:10.1038/labinvest.2010.203; published online 31 January 2011

KEYWORDS: amyotrophic lateral sclerosis; astrocyte; c-Ret; glial cell line-derived neurotrophic factor; microglia; motor neuron

Amyotrophic lateral sclerosis (ALS) is a fatal neurodegenerative disease characterized by selective degeneration of motor neurons located in the spinal cord, brain stem, and motor cortex, resulting in progressive atrophy and paralysis of limb, bulbar, and respiratory muscles. ${ }^{1-4}$ Mutations of the free radical scavenging enzyme superoxide dismutase-1 (SOD1) are a cause of familial ALS. ${ }^{1}$ Transgenic mice expressing human mutant SOD1 develop age-dependent clinical and pathological features closely mirroring those found in human ALS, and thus provide a comprehensive model to study pathogenic mechanisms that may underlie the human disease. $^{5-9}$ In ALS, oxidative damage of spinal cord proteins occurs, and motor neurons are particularly vulnerable to oxidative stress, a phenomena attributed to low levels of antioxidant enzymes, a high content of easily oxidized substrates, and an inherently high flux of ROS generated during energy metabolism. ${ }^{1,3,4}$ Another prominent feature of ALS pathology is the generation and migration of new cells, especially microglia, within and around damaged regions. ${ }^{10}$ Microglia, the macrophages of the CNS, has long been suspected as central components in neurodegenerative diseases where their role may include secretion of trophic or toxic molecules. The interplay between motor neurons and glial cells is important in the clinical progression of both familial and sporadic motor neuron diseases. The release of reactive oxygen and nitrogen species or cytokines from microglia leads to the damage of motor neurons. ${ }^{11}$ This accumulating evidence suggests the contribution of microglia to non-cell autonomous motor neuron death in ALS animal models.

The c-Ret, a membrane-associated receptor protein tyrosine kinase, has been shown to be a component of the glial cell line-derived neurotrophic factor (GDNF) receptor complex. ${ }^{12,13}$ The GDNF signaling is mediated through the tyrosine kinase properties of c-Ret. It is essential for signal transduction to form the complex of GDNF, GDNFR- $\alpha$ and $\mathrm{c}$-Ret, and the phosphorylation of several tyrosine residues of

\footnotetext{
${ }^{1}$ VA Boston Healthcare System, Boston, MA, USA; ${ }^{2}$ WCU Neurocytomics Group, Department of Biomedical Sciences, Seoul National University College of Medicine, Seoul, Republic of Korea; ${ }^{3}$ Department of Neurology and Pathology, Boston University School of Medicine, VA Boston Healthcare System, Boston, MA, USA and ${ }^{4}$ Department of Medicine (Neurology) and Brain Research Centre, University of British Columbia Hospital, University of British Columbia, Vancouver, BC, Canada Correspondence: Professor H Ryu, PhD or Professor J Lee, PhD, Department of Neurology and Pathology, Boston University School of Medicine, VA Boston Healthcare System, Building 1A, Room 105, Boston, MA 02130, USA.

E-mail: hoonryu@bu.edu or junghee@bu.edu

*These two authors contributed equally to this work.

Received 14 April 2010; revised 27 September 2010; accepted 28 October 2010
} 
c-Ret is a crucial step in the intracellular signaling pathway. ${ }^{14}$ Tyrosine (Tyr) 1062 has been identified as a major docking site of the C-terminal regulatory domain in seven of the potential auto-phosphorylation sites. ${ }^{15}$ It is thought that the phosphorylation of Tyr 1062 is important for cell survival, growth, and differentiation along with downstream signaling kinase cascades through Akt and IKKs. ${ }^{16,17}$ Yamamoto et $\mathrm{al}^{18}$ reported that c-Ret is expressed in the specific subsets of neurons, including motor neurons, paralleling the distribution of GDNF-responsive neurons. ${ }^{18}$ GDNF is considered as a potential therapeutic candidate for ALS as well as for other neuromuscular disorders. ${ }^{19,20}$ In this context, GDNF could rescue motor neurons from the neurodegenerative process in ALS.

Given that c-Ret mRNA and protein are preserved in ALS, it is important to determine how the expression and phosphorylation of c-Ret are regulated in motor neurons versus non-neuronal cells in the spinal cord of ALS. ${ }^{21,22}$ Moreover, the modulation of phosphorylation status of c-Ret in response to oxidative stress remains to be elucidated. We found that the expression of non-phosphorylated and phosphorylated forms (Tyr 905, 1016, and 1062) of c-Ret is differentially expressed in motor neurons as well as in non-neuronal cells in the lumbar spinal cord of ALS transgenic (G93A) mice. We further found that oxidative stress reduces the level of nonphosphorylated and phosphorylated c-Ret in cell line models of ALS.

\section{MATERIALS AND METHODS}

\section{Animals}

Male transgenic ALS mice of the G93A H1 high-expresser strain (The Jackson Laboratory, Bar Harbor, ME, USA) were bred with females with a similar background (B6/SJLF1). Offsprings were genotyped using a polymerase chain reaction (PCR) assay on tail DNA. ${ }^{5}$ To ensure homogeneity of the cohorts tested, we have developed a standardized method to select mice. Body weights were taken at 20 days, and mice were equally distributed according to weight within each experimental cohort. Mice under $8 \mathrm{~g}$ at 20 days were excluded from the experiments. ${ }^{8}$ These experiments were carried out in accordance with the US National Institutes of Health Guide for the Care and Use of Laboratory Animals and were approved by both the Veterans Administration and Boston University Animal Care Committees.

\section{Cell Culture}

Motor neuron-like cells (NSC-34) transfected with pCI-neo expression vector containing human wild-type (WT), hSOD1 ${ }^{\text {wt }}$ (NSC-34/hSOD1 ${ }^{\text {wt }}$ cells) and mutant hSOD1 ${ }^{\mathrm{G} 93 \mathrm{~A}}$ (NSC-34/hSOD $1^{\mathrm{G} 93 \mathrm{~A}}$ cells) were established previously. ${ }^{23-26}$ Cell lines were maintained in Dulbecco's modified Eagle's medium supplemented with $10 \%(\mathrm{v} / \mathrm{v})$ fetal bovine serum, $100 \mathrm{U}$ penicillin per $\mathrm{ml}$ and $0.1 \mathrm{mg}$ streptomycin per $\mathrm{ml}$. Cells were kept in a humidified incubator at $37^{\circ} \mathrm{C}$ under $5 \% \mathrm{CO}_{2}$. Cells were subcultured in $60 \mathrm{~mm}$ dishes at a density of
$1 \times 10^{6}$ cells per well. After $80 \%$ confluence, cells were treated with $100 \mu \mathrm{M}$ hydrogen peroxide $\left(\mathrm{H}_{2} \mathrm{O}_{2}\right)$ for $6 \mathrm{~h}$. For immunostaining experiments, cells were seeded in 24-well plates containing $13 \mathrm{~mm}$ round coverslips at a density of $5 \times 10^{4}$ cells per well. For drug treatment, NSC-34/hSOD $1{ }^{\text {wt }}$ cells and NSC-34/hSOD $1^{\text {G93A }}$ cells in six-well plates were treated with GDNF (100 ng/ml) for $0,10,20,30$ and $60 \mathrm{~min}$.

\section{Small-Interfering RNA Experiment}

NSC-34 cells were transiently transfected with $50 \mathrm{nM}$ of Stealth control RNAi, c-Ret siRNA (GenePharma) using Lipofectamine RNAiMAX (Invitrogen Life Tech). After $48 \mathrm{~h}$, cells were treated with $100 \mu \mathrm{M} \mathrm{H}_{2} \mathrm{O}_{2}$ for 6 and $24 \mathrm{~h}$. The sequences of siRNA are listed in the Supplementary Table 1.

\section{Histopathological Evaluation}

Serially cut lumbar spinal cord tissue sections were immunostained for c-Ret (Santa Cruz Biotechnology, Santa Cruz, CA, USA; dilution 1:500) and phospho-Ret (Tyr 1062) (Santa Cruz Biotechnology; dilution 1:500) using a previously reported conjugated secondary antibody method in spinal cord tissue samples. ${ }^{8,27-29}$ Spinal cord was obtained at autopsy from patients with clinically and pathologically definite ALS and control patients who died of non-neurological diseases. Preabsorption with excess target proteins, omission of the primary antibodies, and omission of secondary antibodies were performed to determine the amount of background generated from the detection assay.

Immunofluorescence Staining and Confocal Microscopy Indirect labeling methods were used to identify c-Ret, phospho-Ret (Tyr 905), phospho-Ret (Tyr 1016), phosphoRet (Tyr 1062), GFAP, SMI32, choline acetyltransferase (ChAT), Iba-1, and APC, ubiquitin in NSC-34 cells, and spinal cord sections from ALS mice as described previously. ${ }^{8,27-29}$ For the confocal microscopy, the specimens were incubated for $1 \mathrm{~h}$ with DyLight 594 donkey anti-rabbit IgG antibody, DyLight 488 donkey anti-goat IgG antibody and DyLight 488 donkey anti-mouse IgG antibody (Jackson ImmunoResearch, Baltimore Pike, PA, USA; 1:400) after the incubation of primary antibody. Images were analyzed using an Olympus FluoView FV10i confocal microscope (Olympus, Tokyo, Japan). Preabsorption with excess target protein or omission of primary antibody was used to show antibody specificity and background generated from the detection assay.

\section{Western Blotting}

Tissue lysates and subcellular fractions from WT and G93A mice were prepared using an ice-cold cell extraction buffer containing $50 \mathrm{mM}$ Tris- $\mathrm{HCl}, \mathrm{pH} 7.4 ; 150 \mathrm{mM} \mathrm{NaCl} ; 2 \mathrm{mM}$ EDTA; $1 \%$ Triton X-100; $1 \mathrm{mM}$ PMSF; $10 \mathrm{mg} / \mathrm{ml}$ leupeptin; $1 \mathrm{mM}$ pepstatin; $1 \mathrm{mM} \mathrm{N}$-ethylmleimide; $2 \mathrm{mM} \mathrm{Na}_{3} \mathrm{VO}_{4}$; $20 \mathrm{mM}$ sodium pyrophosphate; and $50 \mathrm{mM} \mathrm{NaF}^{27-29}$ Lysates were centrifuged at 15000 r.p.m. at $4{ }^{\circ} \mathrm{C}$ for $30 \mathrm{~min}$, and the 
supernatant fraction was kept. For extraction of detergentinsoluble protein, the pellet was suspended in ice-cold cell extraction buffer, sonicated three times for $10 \mathrm{~s}$, and centrifuged twice at 3000 r.p.m. at $4{ }^{\circ} \mathrm{C}$ for 1 min to obtain Triton $\mathrm{X}$-100-resistant pellets. The protein concentration was quantified, and the samples were boiled for $10 \mathrm{~min}$ with Laemmli buffer (100 mM Tris-HCl, pH 6.8; 4\% SDS; 200 mM dithiothreitol; $20 \%$ glycerol; $2 \%$ SDS; $0.2 \%$ bromophenol blue; $10 \mathrm{mg} / \mathrm{ml}$ aprotinin; and $10 \mathrm{mg} / \mathrm{ml}$ leupeptin) at $100{ }^{\circ} \mathrm{C}$. In general, $30 \mathrm{mg}$ of proteins was electrophoresed on $10 \%$ SDS-polyacrylamide gel and transferred to nitrocellulose membrane. Membranes were blocked in 5\% skim milk in TBST (Tris, pH 7.4; $150 \mathrm{mM} \mathrm{NaCl}$; and $0.05 \%$ Tween 20) for $30 \mathrm{~min}$ at room temperature. Blots were probed with primary antibodies overnight at $4{ }^{\circ} \mathrm{C}$. The antibodies used were the following: c-Ret, phospho-Ret (Tyr 1062), Bax (Santa Cruz Biotechnology; dilution 1:500), phospho-Ret (Tyr 905) (Cell Signaling Technology, Danvers, MA, USA; dilution 1:500), phospho-Ret (Tyr 1016) (Invitrogen, Camarillo, CA, USA; dilution 1:500), ubiquitin (Dako, Carpinteria, CA, USA; dilution 1:500), and $\beta$-actin (Sigma; dilution 1:2000). Horseradish peroxidase-conjugated secondary IgG antirabbit IgG (Bio-Rad Laboratories, Richmond, CA, USA) was used at 1:5000.

\section{Immunoprecipitation Analysis}

Cell pellets were suspended in lysis buffer containing protease inhibitors, and lysates were centrifuged at 14000 r.p.m. for $10 \mathrm{~min}$. Equal amounts of protein were precipitated with cRet antibody at $4{ }^{\circ} \mathrm{C}$ for $6 \mathrm{~h}$ on a rocker. Protein A/G agarose beads (Santa Cruz) were added to each sample and incubated at $4{ }^{\circ} \mathrm{C}$ for $1 \mathrm{~h}$. Immunoprecipitates were collected by centrifugation and then washed three times with the same buffer. The agarose beads were resuspended in $30 \mu \mathrm{l}$ of $1 \times$ SDSPAGE sample buffer and incubated at $100{ }^{\circ} \mathrm{C}$ for $10 \mathrm{~min}$ to release the proteins. After a pulse spin, the supernatants were loaded.

\section{Quantitative RT-PCR Analysis}

Fifty nanograms of RNA were used as a template for quantitative RT-PCR amplification, using SYBR Green Real-time PCR Master Mix (Toyobo, Japan). Primers were standardized in the linear range of cycle before the onset of the plateau. The sequence of the primers was as follow: c-Ret forward, 5'-CAGGAGCCTGTCTATCTCAGA-3'; c-Ret reverse, 5'-CT GGCAGTTTTCCACACAGA-3'; GAPDH forward, 5'-TGTG TCCGTCGTGGATCTGA-3'; GAPDH reverse, $5^{\prime}$-CCTGCTT CACCACCTTCTTGA- $3^{\prime}$. GAPDH was used as an internal control. Two-step PCR thermal cycling for DNA amplification and real-time data acquisition were performed with an ABI StepOnePlus ${ }^{\mathrm{TM}}$ Real-Time PCR System using the following cycle conditions: $95^{\circ} \mathrm{C}$ for $1 \mathrm{~min} \times 1$ cycle, and $95^{\circ} \mathrm{C}$ for $15 \mathrm{~s}$, followed by $60^{\circ} \mathrm{C}$ for $1 \mathrm{~min} \times 40$ cycles. Fluorescence data were analyzed by the ABI StepOnePlus software and expressed as $C_{\mathrm{t}}$, the number of cycles needed to generate a fluorescent signal above a predefined threshold. The ABI StepOnePlus software set baseline and threshold values.

\section{Statistics}

The data are expressed as means \pm s.e.m. Statistical comparisons of data were performed using Student's $t$-test.

\section{RESUTLS \\ The Level of c-Ret is Altered in the Spinal Cord of Human and ALS (G93A) Mice}

In the first series of experiment, we determined whether the level of c-Ret is changed between control and sporadic ALS (SALS) patient by immunohistochemistry. We found that the immunoreactivity of c-Ret is found in motor neurons of the ventral horn of spinal cord sections in control, but not in SALS patient (Figure 1a). A marked increase in the immunoreactivity of c-Ret was shown in non-neuronal cells (Figure 1a). Next, we analyzed the distribution of c-Ret in the ventral horn of lumbar spinal cord sections from WT littermate control mice and G93A mice when they reached at 50, 90, and 120 days of age (Figure 1b). Similarly to human beings, c-Ret immunoreactivity was found mainly in cytoplasmic compartment of motor neurons in WT mice, while its expression was elevated in nonneuronal cells in the spinal cord of G93A mice in an agedependent manner. The increase of c-Ret immunoreactivity was detected in the atrophic motor neurons and other degenerating neurons in G93A mice from 90 days of age. A significant increase of c-Ret staining was seen in nonneuronal cells of G93A mice in comparison to control mice at 120 days of age (Figure 1c). Western blot analysis showed constant levels of c-Ret protein both in the spinal cords of WT mice and G93A mice at 50, 70, 90, and 120 days of age (Figure 1d). Immunohistochemistry data supported that the insignificant change of total c-Ret level in the lumbar spinal cord was due to c-Ret expression in non-neuronal cells despite the reduction of immunoreactivity of c-Ret in motor neurons (Figure 1b).

We further showed an age-dependent increase of phosphorylated (p)-Ret (Tyr 1062)-positive non-neuronal cells within the ventral horn of lumbar spinal cord sections from G93A mice as compared with WT mice (Figure 2). A significant increase in the immunoreactivity of p-Ret Tyr 1062 in non-neuronal cells was observed at 90 and 120 days of age in comparison to control mice (Figure 2a). p-Ret (Tyr 1062) immunoreactivity was observed in the nucleus of motor neurons in WT mice, whereas p-Ret (Tyr 1062) was shown as punctate structures in the cytoplasm of motor neurons in G93A mice at 120 days of age. Confocal microscopy showed that p-Ret (Tyr 1062) and SMI-32, a motor neuron marker, were not colocalized within the ventral horn of lumbar spinal cord G93A mice as compared with WT mice at 120 days of age (Figure $2 \mathrm{~b}$ ).

p-Ret (Tyr 905) and SMI32 were colocalized in motor neurons both in WT and G93A mice (Figure 3a). Interestingly, 
a
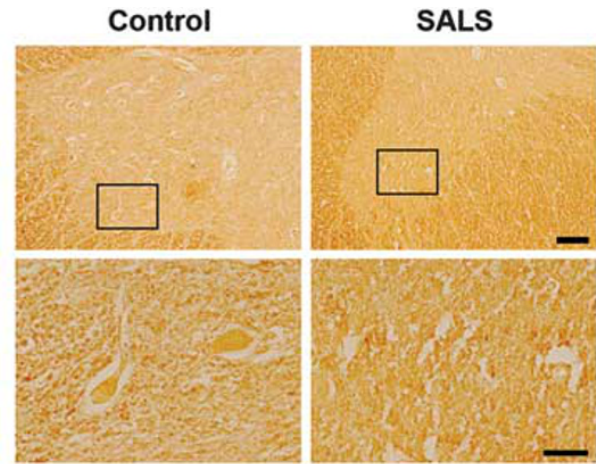

b

b
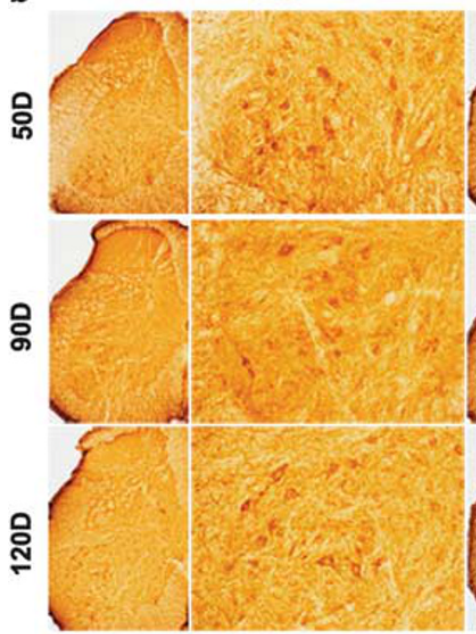

SALS

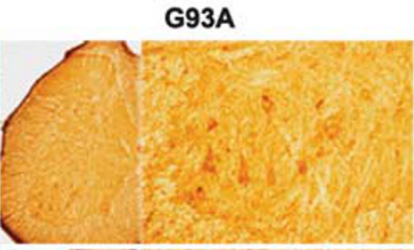

C
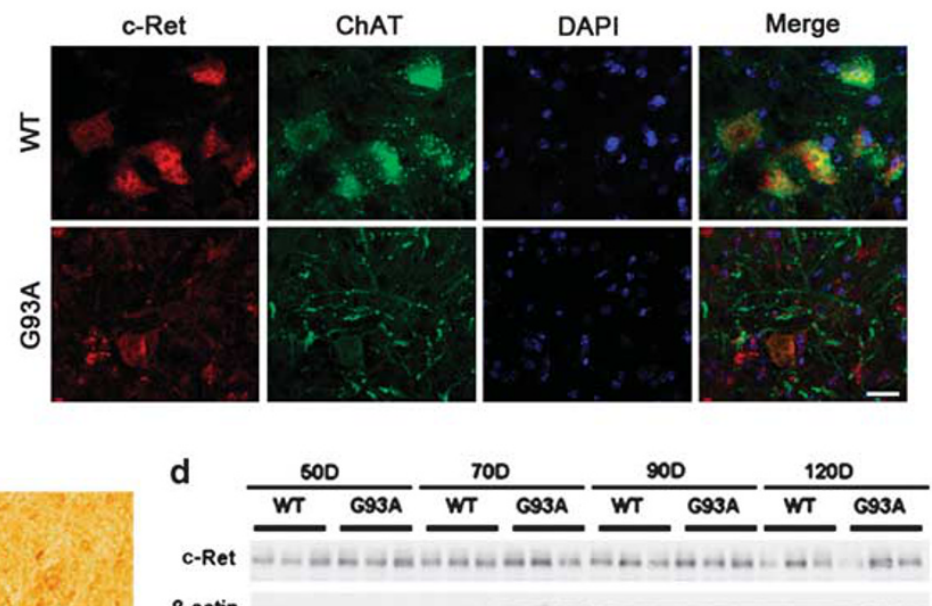

B-actin

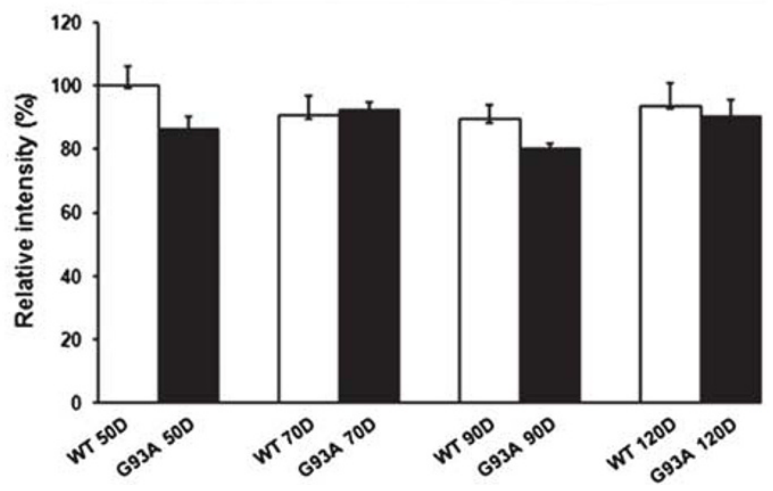

Figure 1 The c-Ret is altered in amyotrophic lateral sclerosis (ALS). (a) c-Ret immunoreactivity was observed in motor neurons of control, while its expression was observed in non-neuronal cells in the spinal cord of human sporadic ALS (SALS). Scale bars = top, $250 \mu \mathrm{m}$; bottom, $100 \mu \mathrm{m}$. (b) c-Ret immunoreactivity in the ventral horn of lumbar spinal cord sections in wild-type (WT) and G93A ALS mice at 50, 90, and 120 days of age. c-Ret immunoreactivity was observed mainly in motor neurons of WT mice, while its expression was elevated in non-neuronal cells in G93A mice in an agedependent manner. Scale bars =left, $250 \mu \mathrm{m}$; right, $100 \mu \mathrm{m}$. (c) Double immunofluorescence staining and confocal microscopy for c-Ret (red) and choline acetyltransferase (ChAT: a motor neuron marker) (green) in the spinal cord of WT and G93A mice at 120 days of age. c-Ret immunoreactivity was observed in non-neuronal (ChAT-negative) cells in the lumbar spinal cord of G93A mice. The nucleus was stained with 4',6-diamidino-2-phenylindole (DAPI). Scale bars (white): $20 \mathrm{~mm}$. (d) Western blot analysis of c-Ret in the spinal cords of WT and G93A mice at 50, 70, 90, and 120 days of age. c-Ret signals were normalized to $\beta$-actin signal. Band densities were analyzed using an image analyzer and are expressed as percentages of controls. Bars indicate means \pm s.d.

p-Ret (Tyr 905) immunoreactivity was observed in neurofilament aggregates in motor neurons of G93A mice, whereas the punctate and diffuse pattern of p-Ret (Tyr 905) immunoreactivity was mainly found in the cytoplasmic compartment in WT mice. In addition, p-Ret (Tyr 905) was colocalized with ubiquitin in neurofilament aggregates within motor neurons of G93A mice (Figure 3b). p-Ret (Tyr 1016) and SMI32 were also co-localized in motor neurons in both WT and G93A mice, but p-Ret (Tyr 1016) immunoreactivity was generally reduced and shown as punctate and granular patterns in the cytoplasm and nucleus of motor neurons in G93A mice (Figure 3c).

As it appeared that p-Ret (Tyr 1062) was also localized to non-neuronal cells, we performed double staining using p-Ret (Tyr 1062) and GFAP, an astrocyte marker. We found that c-Ret and GFAP were not colocalized in either WT or G93A mice at 120 days of age (Figure $4 \mathrm{a}$ ). In addition, p-Ret
(Tyr 1062) and APC, an oligodendrocyte marker, were not colocalized and, in fact, no overlap was observed in WT mice (Figure 4b). However, p-Ret (Tyr 1062) and APC were partially colocalized in some oligodendrocytes of G93A mice. Importantly, p-Ret (Tyr 1062) was significantly colocalized in Iba-1-positive activated microglial cells in the lumbar spinal cord of G93A mice at 120 days of age, whereas p-Ret (Tyr 1062) was not colocalized with Iba-1-positive cells in WT mice (Figure 5a). Notably, non-phosphorylated and phosphorylated forms of c-Ret immunoreactivities were markedly elevated in activated microglia of the lumbar spinal cord of ALS mice in an age-dependent manner. Otherwise, quantitative RT-PCR analysis showed G93A mice $(n=6)$ express c-Ret mRNA at slightly higher levels than WT mice $(n=6)$ (Figure 5b). The increase of c-Ret mRNA was not statistically significant. Double immunofluorescence staining data provided evidence that the increased c-Ret mRNA is derived 
a
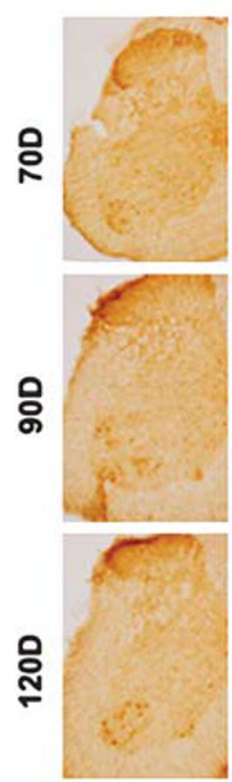

WT

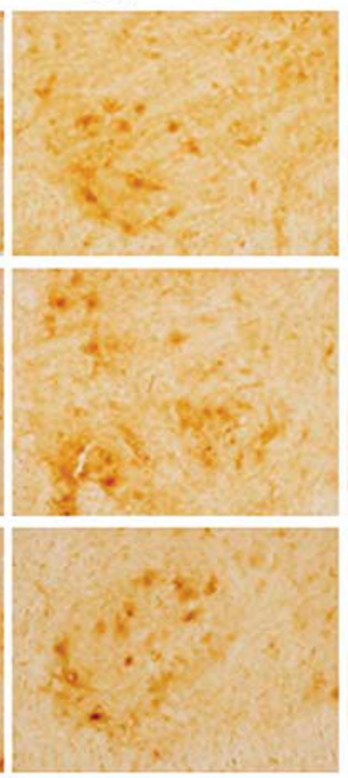

G93A

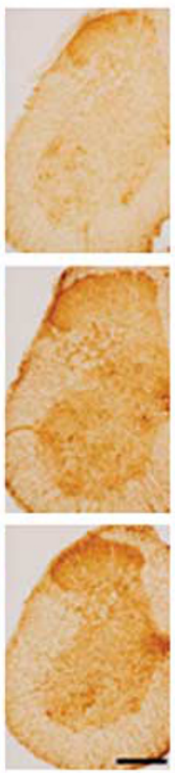

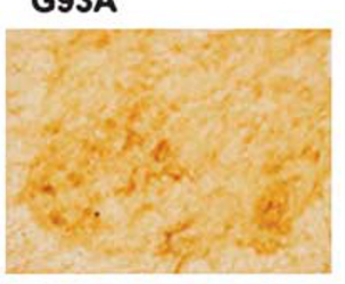
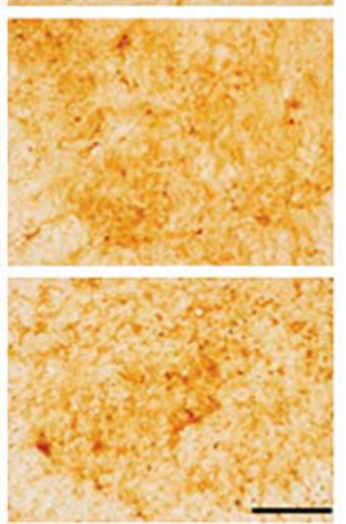

b
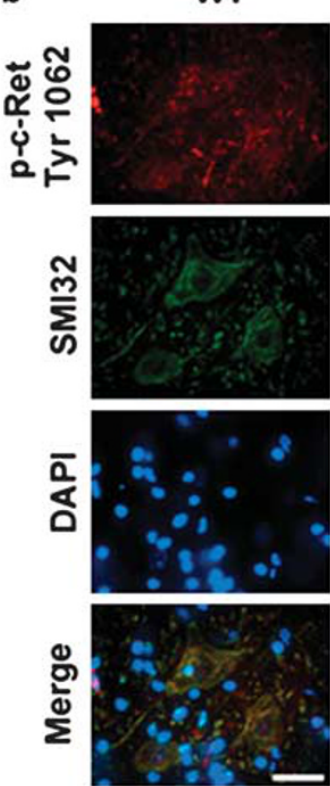

G93A
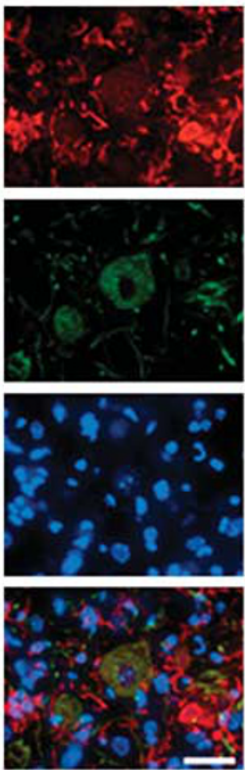

Figure 2 Phosphorylated (p)-c-Ret is altered in amyotrophic lateral sclerosis (ALS). (a) The immunoreactivity of p-c-Ret (Tyr 1062) in the ventral horn of lumbar spinal cord sections in wild-type (WT) and G93A mice at 70, 90, and 120 days of age. p-c-Ret (Tyr 1062) immunoreactivity was observed in motor neurons of WT mice, while its expression was elevated in non-neuronal cells in G93A mice in an age-dependent manner. Scale bars (black); left, $250 \mu \mathrm{m}$; right, $100 \mu \mathrm{m}$. (b) Double immunofluorescence staining and confocal microscopy for p-c-Ret (Tyr 1062) (red) and SMI32 (a motor neuron marker) (green) in the spinal cord of WT and G93A mice at 120 days of age. The immunoreactivity of p-c-Ret (Tyr 1062) was elevated in non-neuronal (SMI32negative) cells in the lumbar spinal cord of G93A mice. The nucleus was stained with 4',6-diamidino-2-phenylindole (DAPI). Scale bars (white): $20 \mu$ m.

a
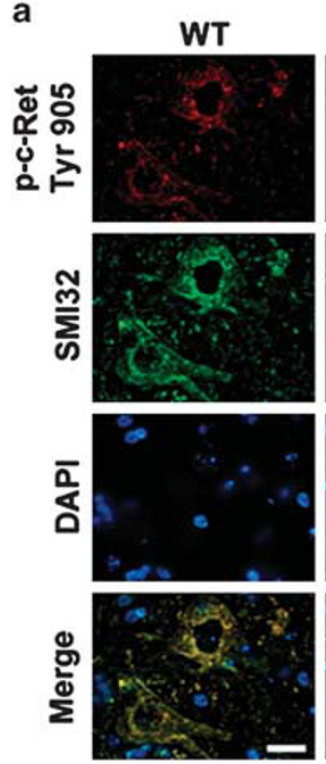

G93A
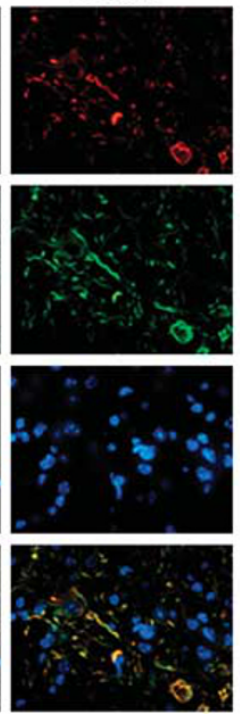

b
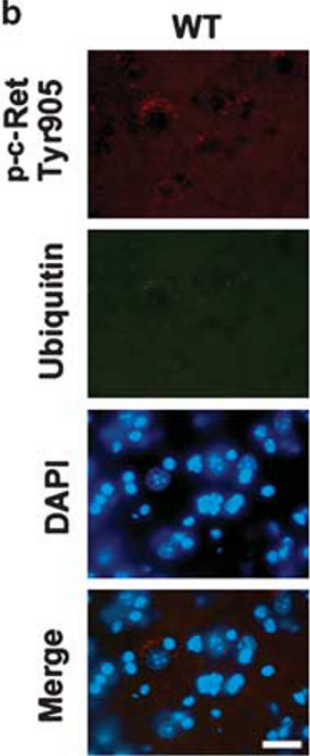

G93A
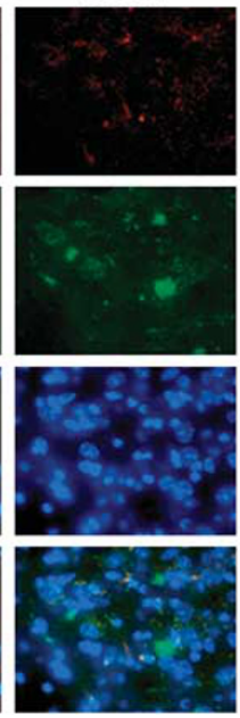

C
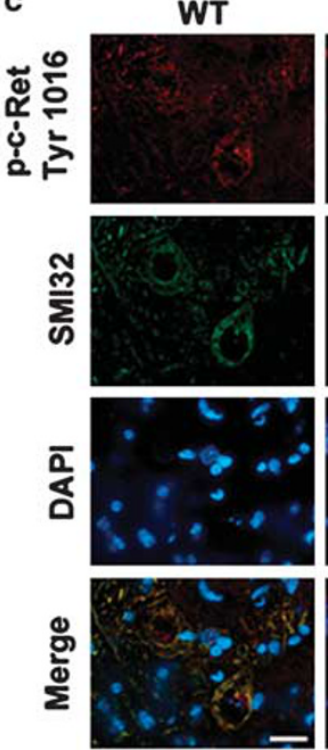

G93A
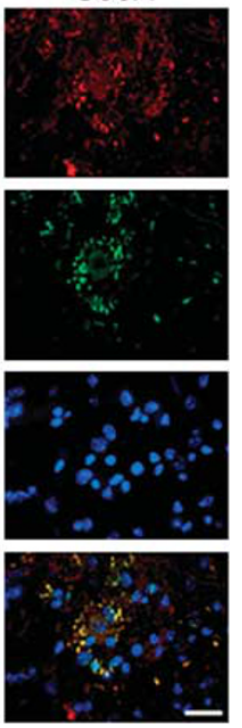

Figure 3 Phosphorylated (p)-c-Ret is found in punctate compartments of motor neurons. (a) Double immunofluorescence staining and confocal microscopy for p-c-Ret (Tyr 905) and SMI32 in the spinal cord of wild-type (WT) and G93A amyotrophic lateral sclerosis (ALS) mice at 120 days of age. p-c-Ret (Tyr 905) (red) and SMI32 (green) were colocalized in motor neurons in WT and G93A mice. The diffused staining of p-c-Ret (Tyr 905) immunoreactivity was found mainly in cell body and axonal arborization in WT mice. In contrast, the punctate structure of p-Ret (Tyr 905$)$ immunoreactivity was observed in the fibril tangles of G93A mice. (b) Colocalization of p-Ret (Tyr 905) and ubiquitin conjugates was elevated in the spinal cord of G93A mice in comparison to WT mice at 120 days of age. (c) Double immunofluorescence staining and confocal microscopy for p-c-Ret (Tyr 1016) and SMI32 in the spinal cord of WT and G93A mice at 120 days of age. p-c-Ret (Tyr 1062) and SMI32 were colocalized in motor neurons of WT and G93A mice. p-c-Ret (Tyr 1016) immunoreactivity (red) was observed in the cell body of SMI32-positive motor neurons (green) in WT mice. In contrast, p-c-Ret (Tyr 1016) immunoreactivity was found in the cytosolic punctate compartment of motor neurons in the G93A mice. The nuclei were stained with 4',6-diamidino-2-phenylindole (DAPI). Scale bars (white): $20 \mu \mathrm{m}$. 
a
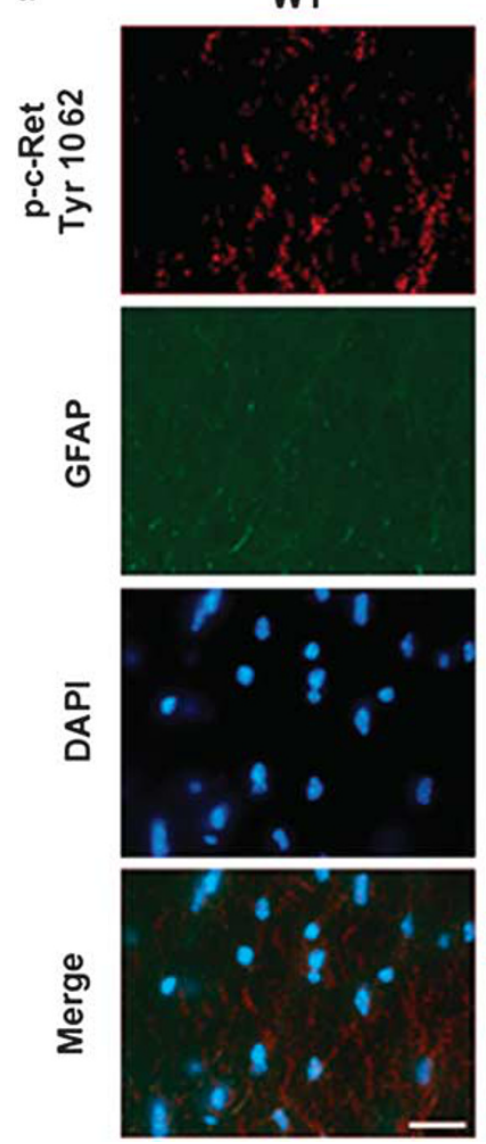

G93A
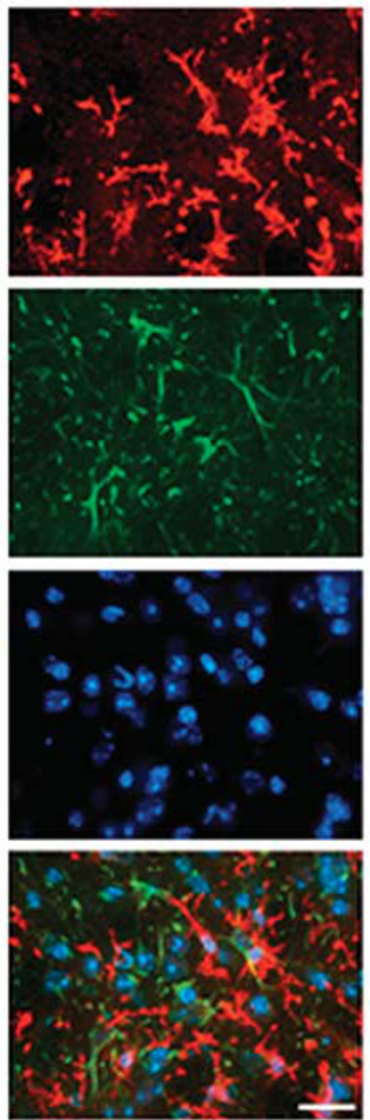

b
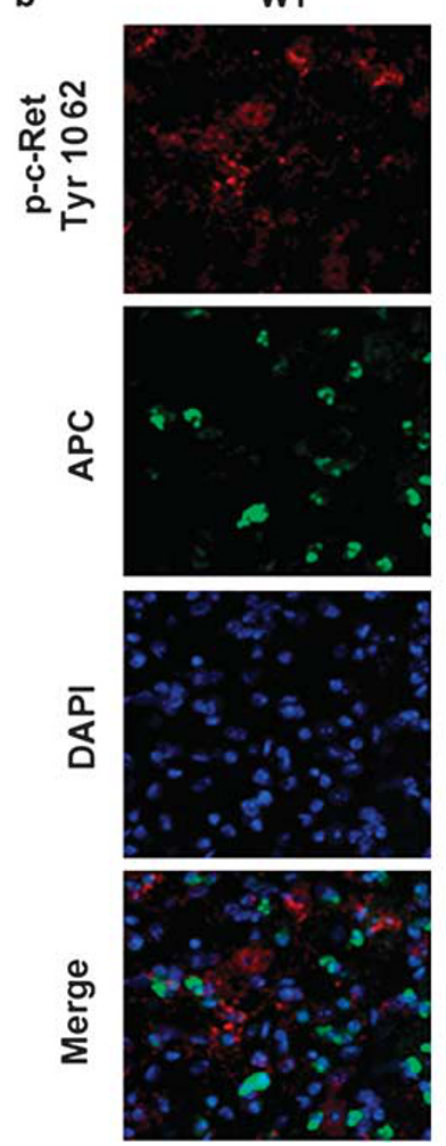

G93A
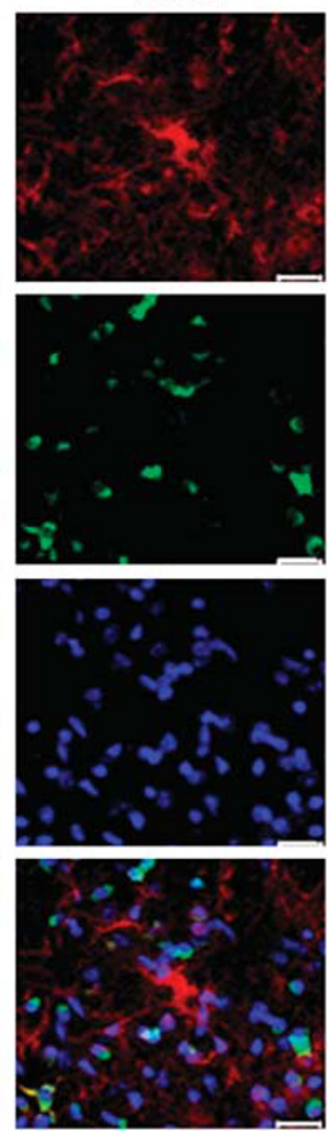

Figure 4 Phosphorylated ( $p$ )-c-Ret is increased in non-neuronal cells of amyotrophic lateral sclerosis (ALS) mice. (a) Double immunofluorescence staining and confocal microscopy for p-c-Ret (Tyr 1062) and glial fibrillary acidic protein (GFAP) (an active astrocyte marker) in wild-type (WT) and G93A mice at 120 days of age. p-c-Ret (Tyr 1062) immunoreactivity (red) was not colocalized with GFAP (green) in the lumbar spinal cord of WT nor in G93A mice. (b) Double immunofluorescence staining and confocal microscopy for p-c-Ret (Tyr 1062) and adenomatous polyposis coli (APC) (an oligodendrocyte marker) in WT and G93A mice at 120 days of age. p-c-Ret (Tyr 1062) immunoreactivity (red) was not found in APC-positive cells (oligodendrocytes) (green) in the spinal cord of WT mice, but p-Ret Tyr 1062 was colocalized partially in the oligodendrocytes (APC-positive) cells in G93A mice. Scale bars (white): $20 \mu \mathrm{m}$.

from microglial cells despite the level of c-Ret was reduced in motor neurons (Figure 5a).

\section{The Levels of c-Ret and p-c-Ret (Tyr 905, 1016, and 1062) are Altered in the ALS (G93A) Cell Line Model}

NSC-34 cells stably transfected with mutant WT hSOD1 and mutant hSOD1 ${ }^{\mathrm{G} 93 \mathrm{~A}}$ have been used as a cellular model of ALS for studying numerous pathological characteristics of the disease. ${ }^{23-26,30,31}$ We found that non-phosphorylated and phosphorylated forms of c-Ret (Try 905, 1016, and 1062) immunoreactivities were decreased in NSC-34/hSOD1 ${ }^{\mathrm{G} 93 \mathrm{~A}}$ cells in comparison to mock NSC-34 and WT-hSOD1 cells (Figure 6a-d). Concurrently with the immunofluorescence staining results, the western blot showed a reduced protein level of non-phosphorylated and phosphorylated forms of c-Ret in NSC-34/hSOD ${ }^{\mathrm{G} 93 \mathrm{~A}}$ cells in comparison to NSC34 and NSC-34/hSOD $1^{\text {wt }}$ in the soluble fraction, whereas an increased protein level of c-Ret is found in the insoluble fraction (Figure 6e and f). In addition, we examined whether
c-Ret is ubiquitinated in motor neurons under ALS condition. By means of immunoprecipitation of NSC-34, NSC$34 / \mathrm{hSOD}^{\mathrm{wt}}$, and NSC-34/hSOD1 ${ }^{\mathrm{G} 93 \mathrm{~A}}$ cell lysates with c-Ret antibody followed by a western blot probing with ubiquitin antibody, we confirmed that an increase of c-Ret ubiquitination in NSC-34/hSOD ${ }^{\mathrm{G} 93 \mathrm{~A}}$ cells in comparison to NSC-34 and NSC-34/hSOD $1^{\mathrm{wt}}$ cells. These data indicate that oxidative stress caused by mutant SOD1 contributes to an increase of c-Ret ubiquitination and aggregation in the insoluble fraction of NSC-34/hSOD $1^{\mathrm{G} 93 \mathrm{~A}}$ (Figure $6 \mathrm{~g}$ ).

\section{Oxidative Stress Modulates the Level of c-Ret and} p-c-Ret (Tyr 905, 1016, and 1062) and GDNF-Dependent c-Ret Signaling is Altered in the ALS (G93A) Cell Line Model

To examine whether c-Ret expression is induced in motor neuron-like cells (NSC-34) in response to oxidative stress, we exposed cells to $\mathrm{H}_{2} \mathrm{O}_{2}$. As we expected, the levels of nonphosphorylated and phosphorylated c-Ret (Tyr 905, 1016, 
a
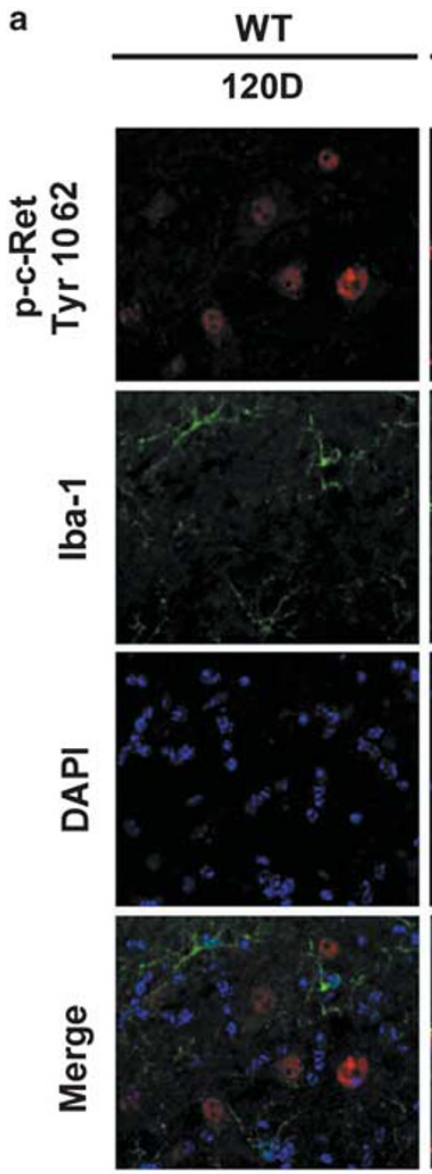
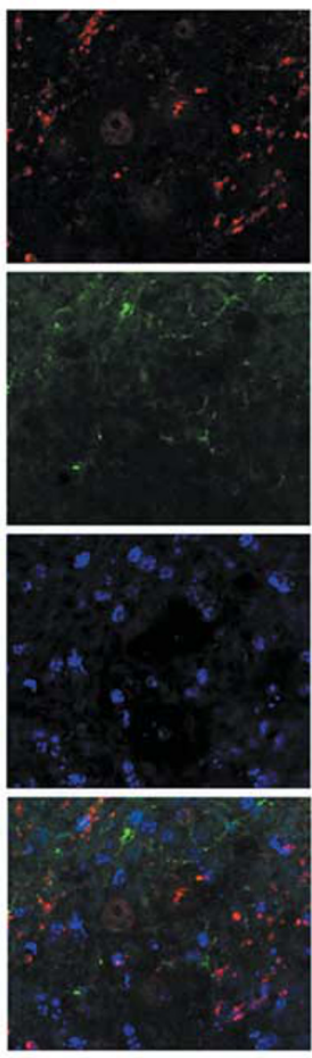

b

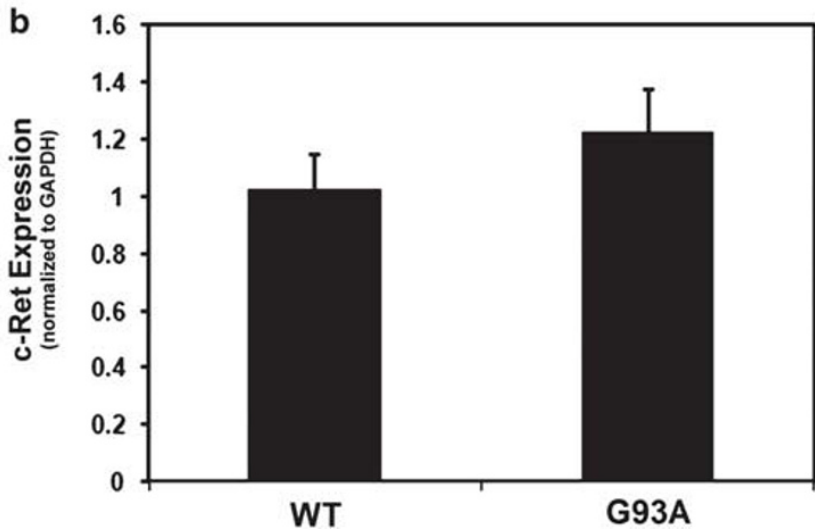

WT

G93A
G93A

70D
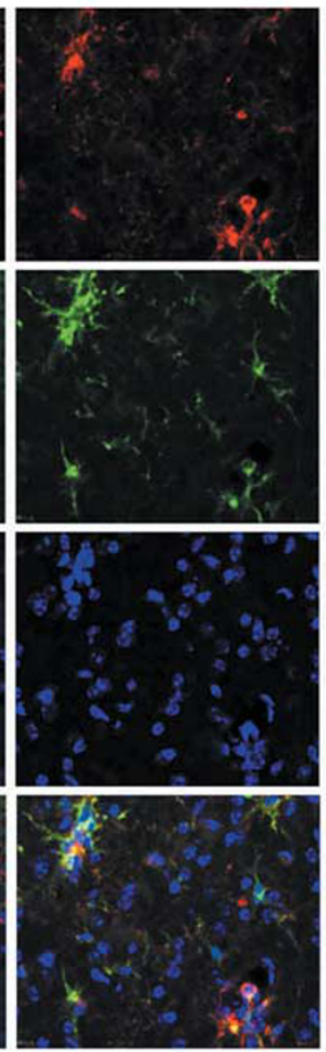

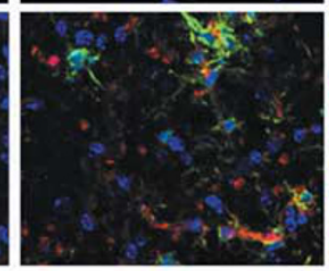

120D
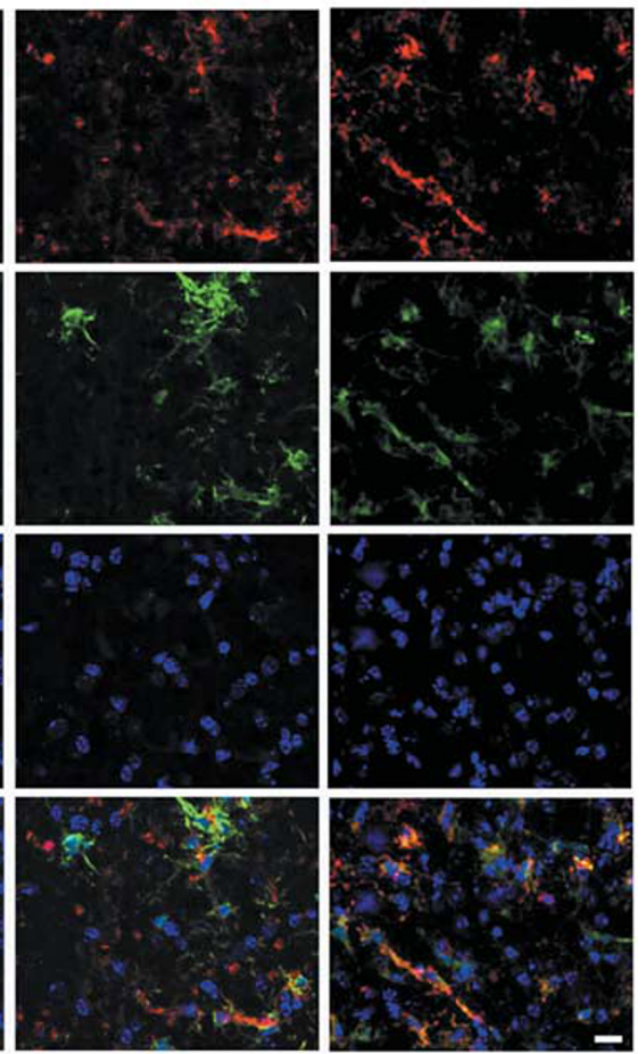

Figure 5 Phosphorylated (p)-c-Ret is highly expressed in microglial cells in amyotrophic lateral sclerosis (ALS) mice. (a) Double immunofluorescence staining and confocal microscopy for p-c-Ret (Tyr 1062) and ionized calcium binding adaptor molecule 1 (Iba-1) (a microglia marker) in wild-type (WT) and G93A mice at 50, 70, 90, and 120 days. p-c-Ret (Tyr 1062) immunoreactivity (red) was found in lba-1-positive (microglial) cells (green) in the spinal cord of G93A mice, but not in WT mice. The immunoreactivity of p-c-Ret (Tyr 1062) was elevated in microglial cells in G93A mice in an age-dependent manner. Scale bars (white): $20 \mu \mathrm{m}$. (b) Quantitative real-time polymerase chain reaction (RT-PCR) analysis of c-Ret mRNA expression. Total RNA samples were extracted from spinal cord of WT littermate control and G93A ALS mice ( $n=6$ each). G93A mice express c-Ret mRNA at slightly higher levels than WT mice. Error bars represent s.e.m.

and 1062) were decreased by oxidative stress in NSC-34 cells (Figure $7 \mathrm{a}$ ). $\mathrm{H}_{2} \mathrm{O}_{2}$ reduced the protein level of c-Ret dose dependently in the soluble fraction, whereas it increased protein levels of $\mathrm{c}$-Ret in the insoluble fraction (Figure 7b). Exposure of NSC-34 cells to 50 and $100 \mu \mathrm{M}$ of $\mathrm{H}_{2} \mathrm{O}_{2}$ for $6 \mathrm{~h}$ resulted in altered cell morphology, that is, either extensive membrane blebbing or shrunken morphology with distinct nuclear condensation (Figure 7c). At this time point, expression of non-phosphorylated and phosphorylated c-Ret (Tyr 905, 1016, and 1062) protein was markedly decreased by 
a

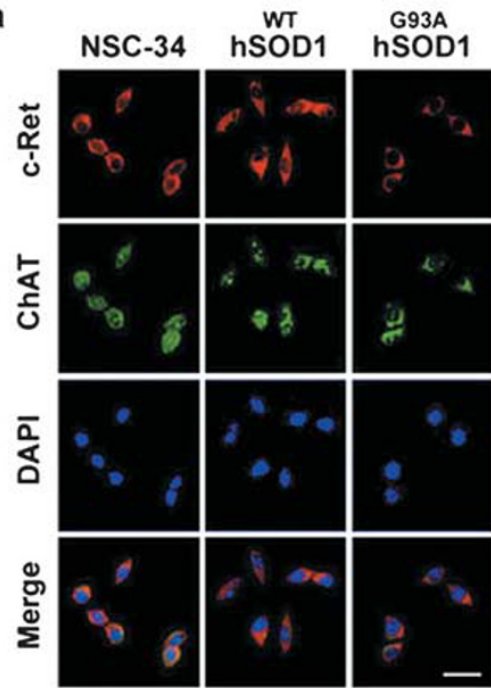

c

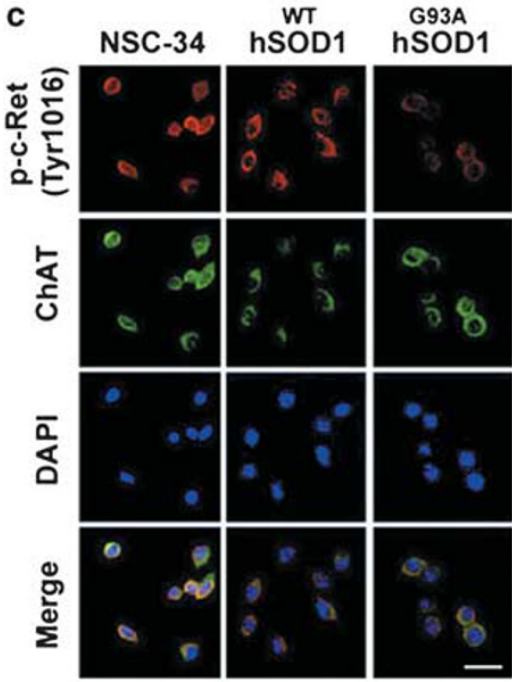

b

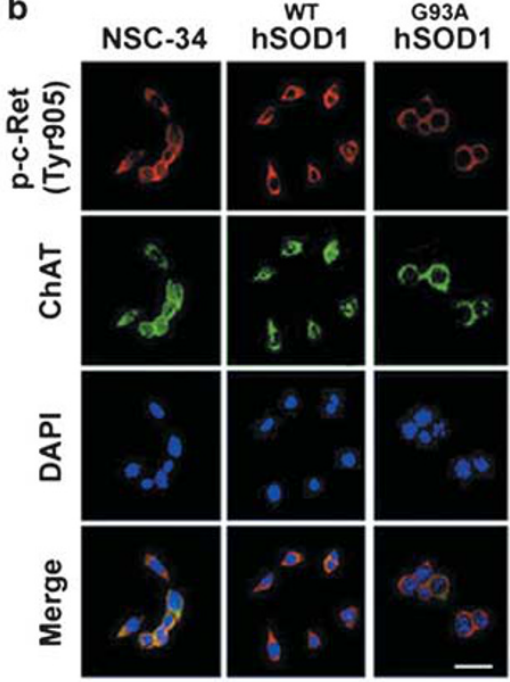

d

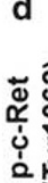

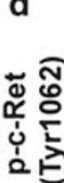

NSC-34 hSOD

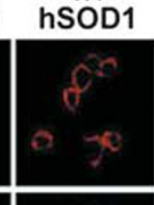

於
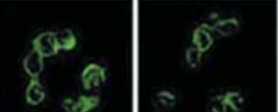

95
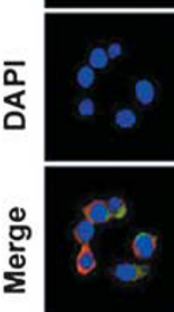

e $\frac{\text { NSC-34 }}{2040} \frac{\text { hSOD1 }}{2040} \frac{\text { hSOD1 }}{2040}$ Protein $(\mu \mathrm{g})$

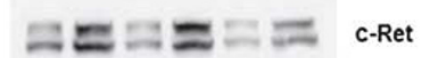

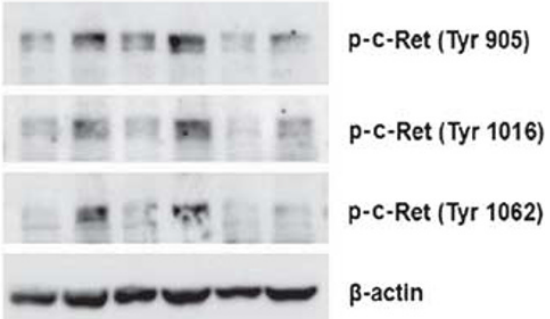

f

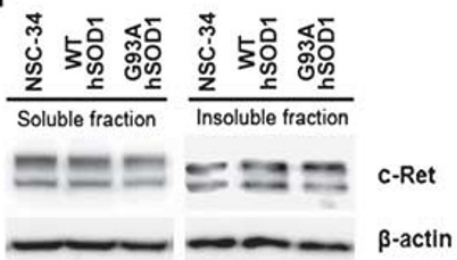

g

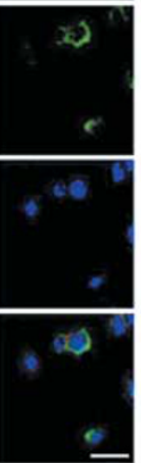

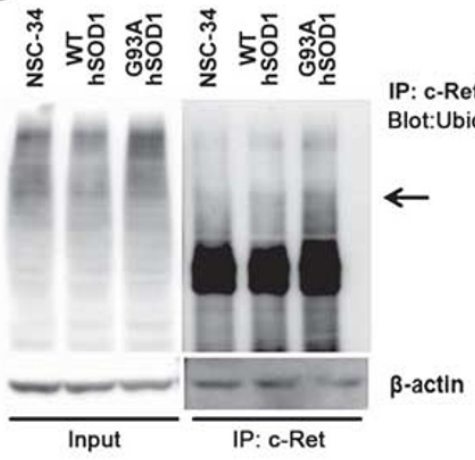

Figure 6 c-Ret and phosphorylated (p)-c-Ret (Tyr 905, 1016, and 1062) are altered in choline acetyltransferase (ChAT)-positive NSC-34 cells. The constitutive expression of c-Ret (a) and p-c-Ret (Tyr 905) (b), p-c-Ret (Tyr 1016) (c), and p-c-Ret (Tyr 1062) protein (d) were found to be ChAT-positive NSC-34, NSC-34/hSOD $1^{\text {wt }}$ and NSC-34/hSOD $1^{\text {G93A }}$ cells. The immunoreactivity of c-Ret and p-c-Ret (Tyr 905, Tyr 1016, and Tyr 1062) were decreased in NSC-34/hSOD $1^{\text {G93A }}$ cells in comparison to NSC-34 and NSC-34/hSOD $1^{\text {wt }}$ cells. The nucleus was stained with 4',6-diamidino-2-phenylindole (DAPI). Scale bars (white): $20 \mu \mathrm{m}$. (e) c-Ret and p-c-Ret were reduced in NSC-34/hSOD $1^{\mathrm{G} 93 \mathrm{~A}}$ in comparison to NSC-34 and NSC-34/hSOD $1^{\text {wt }}$ cells. (f) The level of c-Ret was reduced in the soluble fraction of NSC-34/hSOD $1^{\mathrm{G} 93 \mathrm{~A}}$ in comparison to NSC34 and NSC-34/hSOD $1^{\text {wt }}$ cells, but increased in the insoluble fraction. (g) Immunoprecipitation assay of NSC-34, NSC-34/hSOD $1^{\text {wt }}$, and NSC-34/hSOD $1^{\mathrm{G} 93 \mathrm{~A}}$ cell lysate with c-Ret antibody followed by a western blot probing with ubiquitin. An increased level of ubiquitinated c-Ret was found in NSC-34/hSOD1 ${ }^{\text {G93A }}$ cells in comparison to NSC-34 and NSC-34/hSOD $1^{\text {wt }}$ cells. SOD1, superoxide dismutase-1.

oxidative stress in a dose-dependent manner. In addition, NSC-34 cells, exposed to 50 and $100 \mu \mathrm{M}$ of $\mathrm{H}_{2} \mathrm{O}_{2}$, exhibited cell death after $12 \mathrm{~h}$. Our results indicate that oxidative stress directly affects the protein level of c-Ret and the morphology of NSC-34 cells.

To determine whether GDNF-dependent signaling is impaired in cell line model of ALS or not, we treated NSC-34/ hSOD $1^{\text {wt }}$ and NSC-34/hSOD ${ }^{\text {G93A }}$ cells with GDNF $(100 \mathrm{ng} / \mathrm{ml})$ for various time points $(0,10,20,30$, and $60 \mathrm{~min})$ and checked the phosphorylation status of c-Ret (Figure 7d). Interestingly, the phosphorylation status of c-Ret at Tyr 1016 and 1062 in NSC-34/hSOD ${ }^{\text {G93A }}$ cells was not lasting longer in response to GDNF than in NSC-34/hSOD ${ }^{\text {wt }}$ cells. These data indicate that GDNF signaling via c-Ret phosphorylation is impaired in NSC-34/hSOD ${ }^{\text {G93A }}$ cells. The shorter phosphorylation period of c-Ret by GDNF may not be sufficient enough to trigger a sequential amplification of normal signal transduction via c-Ret in NSC-34/hSOD1 ${ }^{\mathrm{G} 93 \mathrm{~A}}$ cells. To further examine whether knockdown of c-Ret alters the c-Ret phosphorylation-dependent signaling pathway and the induction of Bax, a mitochondrial pro-death protein, NSC-34 cells were transiently transfected with c-Ret siRNAs and the outcome was determined by western blotting. We confirmed that protein levels of non-phosphorylated and 


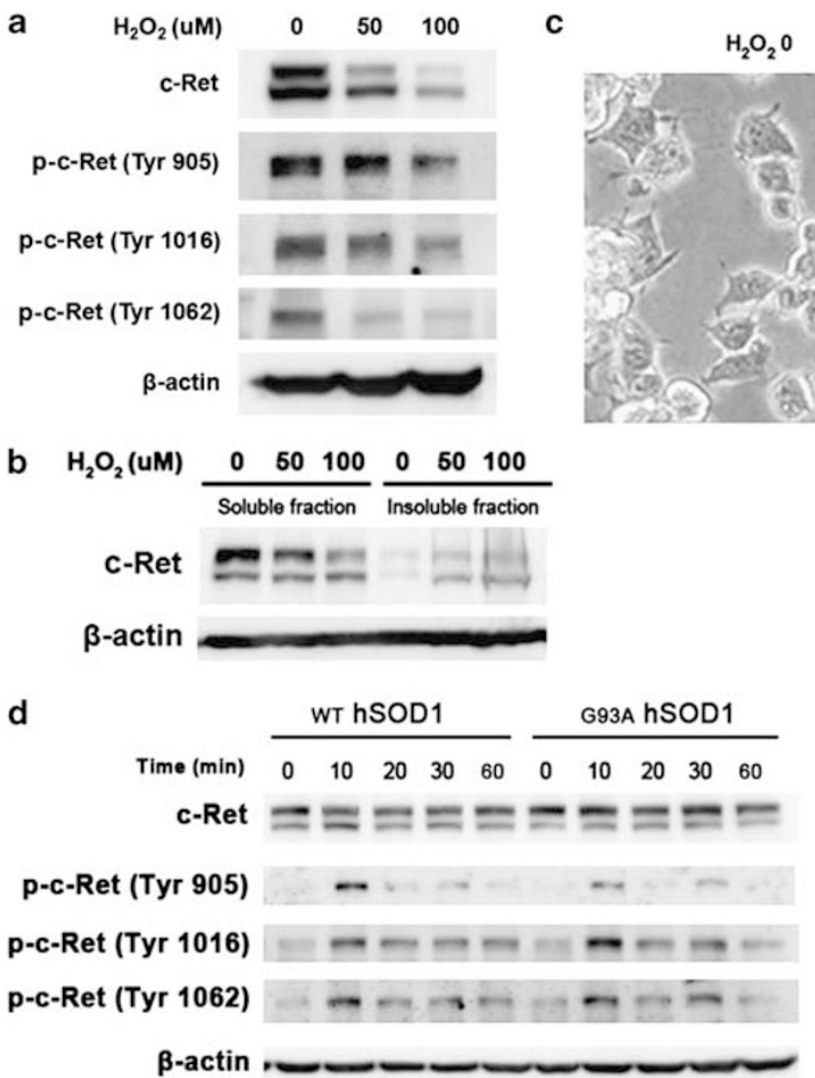

e

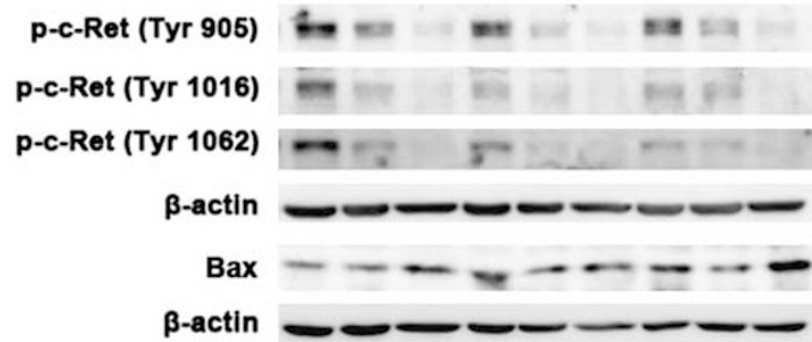

Figure 7 Oxidative stress modulates the levels of non-phosphorylated and phosphorylated forms (Tyr 905, 1016, and 1062) of c-Ret in NSC-34 cells. (a) Western blot analysis of c-Ret and p-c-Ret (Tyr 905, 1016, and 1062) protein levels in NSC-34 cells treated with hydrogen peroxide $\left(\mathrm{H}_{2} \mathrm{O}_{2}\right)(50$ and $100 \mu \mathrm{M})$ for $6 \mathrm{~h}$. $\mathrm{H}_{2} \mathrm{O}_{2}$ reduced the protein level of c-Ret dose dependently. $\beta$-Actin was blotted as a protein loading control. (b) $\mathrm{H}_{2} \mathrm{O}_{2}$ reduced the protein level of c-Ret in the soluble fraction, but increased protein levels of c-Ret in the insoluble fraction in a dose-dependent manner. (c) $\mathrm{H}_{2} \mathrm{O}_{2}$ induced morphological changes of NSC-34 cells. Scale bar (white): $20 \mu \mathrm{m}$. (d) Western blot analysis of c-Ret and p-c-Ret (Tyr 905, 1016, and 1062) in NSC-34/hSOD1 ${ }^{\mathrm{wt}}$ and NSC-34/hSOD $1^{\text {G93A }}$ cells treated with glial cell line-derived neurotrophic factor (GDNF) $(100 \mathrm{ng} / \mathrm{ml})$ for various time points $(0,10,20,30,60 \mathrm{~min})$. (e) c-Ret small interfering RNA (siRNAs) (siRNA-1 and siRNA-2) downregulated the levels of c-Ret and p-c-Ret (Tyr 905, 1016, and 1062) in NSC-34 cells. Oxidative stress $\left(100 \mu \mathrm{M}\right.$ of $\left.\mathrm{H}_{2} \mathrm{O}_{2}\right)$ additively increased Bax expression under c-Ret knockdown condition.

phosphorylated form of c-Ret are downregulated by c-Ret siRNA, but not by control siRNA (Figure 7e). Interestingly, protein level of Bax was elevated in NSC-34 cells transfected with c-Ret siRNAs (Figure 7e). Moreover, loss of function of c-Ret by siRNA resulted in an additive induction of cell death protein (Bax) in response to oxidative stress (Figure 7e).

\section{DISCUSSION}

This study shows that the expression of non-phosphorylated and phosphorylated forms (Tyr 905, 1016, and 1062) of c-Ret is altered in motor neurons of the lumbar spinal cord in ALS transgenic (G93A) mice. The immunoreactivity of phosphorylated forms of c-Ret was colocalized with neurofilament aggregates in motor neurons of ALS mice, but not in WT control mice. Consistent with the in vivo data, both the level of non-phosphorylated and phosphorylated c-Ret (Tyr 905,1016 , and 1062) were decreased by oxidative stress in the cell line model of ALS (NSC-34/hSOD $1^{\mathrm{G} 93 \mathrm{~A}}$ ).

c-Ret expression has been studied in spinal cord motor neurons of patients with ALS using in situ hybridization and immunohistochemistry. ${ }^{22,32}$ c-Ret is a major GDNF ligandreceptor family member that mediates a GDNF signaling pathway in motor neurons. ${ }^{12}$ In general, the c-Ret protein in motor neuron cell bodies is derived from newly synthesized component and retrogradely transported component from nerve terminals. Therefore, the dysregulation of c-Ret protein level in motor neurons of ALS could be due to an impairment of transcription or a abnormal retrograde transport of Ret/GDNF complex in ALS. ${ }^{22,33}$ GDNF is proposed to act in different manners to c-Ret bearing motor neurons, particularly in a pathological state: target-derived mode from muscle, paracrine mode from glial cells, and autocrine mode within neurons. ${ }^{34}$ In this context, the increased CSF levels of GDNF and increased expression of GDNF mRNA in muscle in ALS indicates that the abnormal increase of GDNF may trigger c-Ret pathways in motor neurons that may play a compensatory role for preventing motor neuron degeneration of ALS. ${ }^{35}$ However, the disparity between the decreased level of c-Ret and the increased level of GDNF could subsequently result in a different mechanism being involved in 
neurodegeneration process in motor neurons in later stage of ALS. The details of such a multicomponent signaling pathway remain to be investigated. P-c-Ret Tyr 1062 immunoreactivity has been observed in the nuclei of motor neurons in ALS. ${ }^{21}$ We identified p-c-Ret Tyr 1062 immunoreactivity in motor neuron nuclei in WT mice and found that expression was elevated in microglial cells in the G93A spinal cord in an age-dependent manner. It has been previously shown that c-Ret and p-Ret Tyr 1062 are expressed in microglia in human brain tissue with Parkinson's disease, suggesting that c-Ret expression in active microglial cells might be an important marker of neurodegeneration. ${ }^{36}$

Multiple lines of evidence suggest that non-neuronal cell types modulate the pathogenesis of motor neuronal death in mutant SOD1-mediated neurodegeneration. It is interesting that mutant SOD1 expression in motor neurons influences the onset of disease, but does not influence its progression. ${ }^{37-39}$ Mutant SOD1 toxicity is non-cell autonomous, that is, non-neuronal cells contribute greatly to the pathogenesis of motor neuron damage. ${ }^{40-44}$ The role of inflammation and the activation of microglia in ALS are thought to play a significant role. ${ }^{43}$

GDNF enhances the function of motor neurons and rescues them from neurodegeneration in the early stages of ALS. The phosphorylation status of c-Ret and its tyrosine kinase activity may be important to this process. Oxidative stress may decrease c-Ret levels and its phosphorylation leading to $c$-Ret aggregation and the disruption of GDNF signaling in motor neurons. Oxidative stress-induced expression of c-Ret in microglia may also exacerbate neuronal damage by diverting GDNF from motor neurons or by triggering toxicity through inflammatory pathways as the disease progresses. The regulation of c-Ret expression and its role in microglia remains to be fully determined, but our data suggest that microglial c-Ret expression may be a biomarker of the noncell autonomous motor neuronal death in ALS. ${ }^{40}$ Furthermore, our findings suggest that effects on both neurons and microglia must be considered in the context of therapeutic modulation via c-Ret signaling pathway. ${ }^{29,45}$

Supplementary Information accompanies the paper on the Laboratory Investigation website (http://www.laboratoryinvestigation.org)

\section{ACKNOWLEDGEMENTS}

This study was supported by Rare Disease Research Center Grant from Korea Ministry of Health and Welfare (HR) and WCU Neurocytomics Program Grant (800-20080848) (HR) through SNU from KOSEF. This study was also supported in part by a VA Merit Award and NIH Grants (JL and NK).

\section{DISCLOSURE/CONFLICT OF INTEREST}

The authors declare no conflict of interest.

1. Rosen $\mathrm{DR}$, Siddique $T$, Patterson $\mathrm{D}$, et al. Mutations in $\mathrm{Cu} / \mathrm{Zn}$ superoxide dismutase are associated with familial amyotrophic lateral sclerosis. Nature 1993;362:59-62.
2. Cleveland DW, Rothstein JD. From Charcot to Lou Gehrig: deciphering selective motor neuron death in ALS. Nat Neurosci Rev 2001;2: 806-819.

3. Rowland L, Shneider N. Amyotrophic lateral sclerosis. N Engl J Med 2001;344:1688-1700.

4. Weiss MD, Weydt P, Carter GT. Current pharmacological management of amyotrophic lateral sclerosis and a role for rational polypharmacy. Expert Opin Pharmacother 2004;5:735-746.

5. Gurney ME, Pu H, Chiu AY, et al. Motor neuron degeneration in mice that express a human $\mathrm{Cu}, \mathrm{Zn}$ superoxide dismutase mutation. Science 1994;264:1772-1775.

6. Festoff BW, Suo Z, Citron BA. Prospects for the pharmacotherapy of amyotrophic lateral sclerosis: old strategies and new paradigms for the third millennium. CNS Drugs 2003;17:699-717.

7. Rothstein JD. Of mice and men: reconciling preclinical ALS mouse studies and human clinical trials. Ann Neurol 2003;53:423-426.

8. Ryu H, Smith K, Camelo $\mathrm{Sl}$, et al. Sodium phenylbutyrate prolongs survival and regulates expression of anti-apoptotic genes in transgenic amyotrophic lateral sclerosis mice. J Neurochem 2005;93:1087-1098.

9. Ilzecka J, Stelmasiak Z, Solski J, et al. Plasma amino acids concentration in amyotrophic lateral sclerosis patients. Amino acids 2003;25:69-73.

10. Barbeito LH, Pehar M, Cassina P, et al. A role for astrocytes in motor neuron loss in amyotrophic lateral sclerosis. Brain Res Rev 2004;47:263-274.

11. Agar J, Durham H. Relevance of oxidative injury in the pathogenesis of motor neuron diseases. Amyotroph Lateral Scler Other Motor Neuron Disord 2003;4:232-242.

12. Jing $S$, Wen $D, Y u Y$, et al. GDNF-induced activation of the ret protein tyrosine kinase is mediated by GDNFR-alpha, a novel receptor for GDNF. Cell 1996;85:1113-1124.

13. Zhou R, Niwa S, Homma N, et al. KIF26A is an unconventional kinesin and regulates GDNF-Ret signaling in enteric neuronal development. Cell 2009;139:802-813.

14. Ohiwa $M$, Murakami $H$, Iwashita $T$, et al. Characterization of Ret-ShcGrb2 complex induced by GDNF, MEN 2A, and MEN 2B mutations. Biochem Biophys Res Commun 1997;237:747-751.

15. Liu X, Vega QC, Decker RA, et al. Oncogenic RET receptors display different autophosphorylation sites and substrate binding specificities. J Biol Chem 1996;271:5309-5312.

16. De Vita G, Melillo RM, Carlomagno F, et al. Tyrosine 1062 of RETMEN2A mediates activation of Akt (protein kinase B) and mitogenactivated protein kinase pathways leading to PC12 cell survival. Cancer Res 2006;60:3727-3731.

17. Encinas $M$, Rozen EJ, Dolcet $X$, et al. Analysis of Ret knockin mice reveals a critical role for IKKs, but not PI 3-K, in neurotrophic factorinduced survival of sympathetic neurons. Cell Death Differ 2008;15:1510-1521.

18. Trupp $M$, Arenas $E$, Fainzilber $M$, et al. Functional receptor for GDNF encoded by the c-ret proto-oncogene. Nature 1996;381:785-789.

19. Klein SM, Behrstock S, McHugh J, et al. GDNF delivery using human neural progenitor cells in a rat model of ALS. Hum Gene Ther 2005;16:509-521.

20. Suzuki M, McHugh J, Tork C, et al. Direct muscle delivery of GDNF with human mesenchymal stem cells improves motor neuron survival and function in a rat model of familial ALS. Mol Ther 2008;16: 2002-2010.

21. Yamamoto $M$, Li M, Mitsuma $N$, et al. Preserved phosphorylation of RET receptor protein in spinal motor neurons of patients with amyotrophic lateral sclerosis: an immunohistochemical study by a phosphorylation-specific antibody at tyrosine 1062. Brain Res 2001; 912:89-94.

22. Mitsuma N, Yamamoto M, Li M, et al. Expression of GDNF receptor (RET and GDNFR-alpha) mRNAs in the spinal cord of patients with amyotrophic lateral sclerosis. Brain Res 1999;820:77-85.

23. Cashman NR, Durham HD, Blusztajn JK, et al. Neuroblastoma x spinal cord (NSC) hybrid cell lines resemble developing motor neurons. Dev Dyn 1992;194:209-221.

24. Durham HD, Dahrouge S, Cashman NR. Evaluation of the spinal cord neuron X neuroblastoma hybrid cell line NSC-34 as a model for neurotoxicity testing. Neurotoxicology 1993;14:387-395.

25. Gomes C, Keller S, Altevogt P, et al. Evidence for secretion of $\mathrm{Cu}, \mathrm{Zn}$ superoxide dismutase via exosomes from a cell model of amyotrophic lateral sclerosis. Neurosci Lett 2007;428:43-46. 
26. Gomes C, Palma AS, Almeida R, et al. Establishment of a cell model of ALS disease: Golgi apparatus disruption occurs independently from apoptosis. Biotechnol Lett 2008;30:603-610.

27. Lee J, Kannagi M, Ferrante RJ, et al. Activation of Ets-2 by oxidative stress induces $\mathrm{BCl}-\mathrm{xL}$ expression and accounts for glial survival in amyotrophic lateral sclerosis. FASEB J 2009;23:1739-1749.

28. Lee J, Ryu H, Kowall NW. Motor neuronal protection by L-arginine prolongs survival of mutant SOD1 (G93A) ALS mice. Biochem Biophys Res Commun 2009;384:524-529.

29. Lee J, Ryu H, Kowall NW. Differential regulation of neuronal and inducible nitric oxide synthase (NOS) in the spinal cord of mutant SOD1 (G93A) ALS mice. Biochem Biophys Res Commun 2009;387:202-206.

30. Kirby J, Halligan E, Baptista MJ, et al. Mutant SOD1 alters the motor neuronal transcriptome: implications for familial ALS. Brain 2005;128: 1686-1706.

31. Sathasivam S, Shaw PJ. Apoptosis in amyotrophic lateral sclerosiswhat is the evidence? Lancet Neurol 2005;4:500-509.

32. Duberley RM, Johnson IP, Martin JE, et al. RET-like immunostaining of spinal motoneurons in amyotrophic lateral sclerosis. Brain Res 1998;789:351-354.

33. Naveilhan P, EIShamy WM, Ernfors P. Differential regulation of mRNAs for GDNF and its receptor Ret and GDNFR- $\alpha$ after sciatic nerve lesion in the mouse. Eur J Neurosci 1997;9:1450-1460.

34. Yamamoto M, Sobue G, Yamamoto $K$, et al. Expression of glial cell linederived growth factor mRNA in the spinal cord and muscle in amyotrophic lateral sclerosis. Neurosci Lett 1996;204:117-120.

35. Grundström E, Lindholm D, Johansson A, et al. GDNF but not BDNF is increased in cerebrospinal fluid in amyotrophic lateral sclerosis. Neuroreport 2000;11:1781-1783.
36. Walker DG, Beach TG, Xu R, et al. Expression of the proto-oncogene Ret, a component of the GDNF receptor complex, persists in human substantia nigra neurons in Parkinson's disease. Brain Res 1998; 792:207-217

37. Beers DR, Henkel JS, Xiao Q, et al. Wild-type microglia extend survival in PU.1 knockout mice with familial amyotrophic lateral sclerosis. Proc Natl Acad Sci USA 2006;103:16021-16026.

38. Boillée S, Yamanaka K, Lobsiger CS, et al. Onset and progression in inherited ALS determined by motor neurons and microglia. Science 2006;312:1389-1392.

39. Wang L, Sharma K, Grisotti G, et al. The effect of mutant SOD1 dismutase activity on non-cell autonomous degeneration in familial amyotrophic lateral sclerosis. Neurobiol Dis 2009;35:234-240.

40. Ilieva $\mathrm{H}$, Polymenidou $\mathrm{M}$, Cleveland DW. Non-cell autonomous toxicity in neurodegenerative disorders: ALS and beyond. J Cell Biol 2009; 187:761-772.

41. Clement AM, Nguyen MD, Roberts EA, et al. Wild-type nonneuronal cells extend survival of SOD1 mutant motor neurons in ALS mice. Science 2003;302:113-117.

42. Lino MM, Schneider C, Caroni P. Accumulation of SOD1 mutants in postnatal motoneurons does not cause motoneuron pathology or motoneuron disease. J Neurosci 2002;22:4825-4832.

43. Monk PN, Shaw PJ. ALS: life and death in a bad neighborhood. Nat Med 2006;12:885-887.

44. Pramatarova A, Laganière J, Roussel J, et al. Neuron-specific expression of mutant superoxide dismutase 1 in transgenic mice does not lead to motor impairment. J Neurosci 2001;21:3369-3374.

45. Ryu H, Ferrante RJ. Translational therapeutic strategies in amyotrophic lateral sclerosis. Mini Rev Med Chem 2007;7:141-150. 